\title{
GRANULOMA DE COLESTEROL EN MAMA
}

Juan Carlos Bonilla Jassir MD*, Johana Navarro Mejía MD**, César Poveda MD***, Oscar Eduardo Mendoza Ramírez MD****

\section{Resumen}

El granuloma de colesterol en la glándula mamaria es una rara condición benigna. Su importancia radica en la tendencia a imitar clínica y radiológicamente al carcinoma de mama. Se presenta el caso de una paciente de 48 años con una masa en seno como hallazgo incidental en mamografía de tamizaje.

granuloma, mamografía, ecografía, biopsia.

\section{Abstract}

The cholesterol granuloma of the breast is a rare benign condition. It is often clinically and radiologically indistinguishable from breast cancer. A case of a 48 year old patient with a breast mass found incidentally in a screening mammography is described.

\section{granuloma, mammography, ultrasound, biopsy.}

\section{Presentación del caso}

Se trata de una paciente de 48 años sin masas palpables en sus senos a quien se realiza una mamografía de tamizaje, en la cual se observa un nódulo en el cuadrante superoexterno de la glándula mamaria derecha de carácter inespecífico (Figura 1). Se realiza estudio complementario con ultrasonografía que evidencia un nódulo sólido sospechoso, categorizado como BIRADS-IV (Figura 2). Se destaca la ausencia de antecedentes de carcinoma mamario familiar $\mathrm{u}$ otros factores de riesgo. Se practicó biopsia trucut bajo guía ecográfica observándose en las preparaciones de hematoxilina eosina un proceso inflamatorio crónico conformado por abundantes

Fecha recibido: abril 10 de 2008 - Fecha aceptado: mayo 14 de 2008

* Médico Especialista en patología, Instructor Asistente Fundación Universitaria de Ciencias de la Salud. Hospital de San José, Bogotá D.C. Colombia.

** Residente Il de patología, Fundación Universitaria de Ciencias de la Salud, Bogotá D.C. Colombia.

*** Médico especialista en radiología, Clínica Infantil de Colsubsidio, Bogotá D.C. Colombia.

***** Médico especialista en patología, Hospital de San José, Instructor Asistente, Fundación Universitaria de Ciencias de la Salud. Bogotá D.C. Colombia. espículas de colesterol rodeadas por histiocitos, linfocitos y células gigantes multinucleadas, dispuestos sobre un estroma fibroso (Figura 3). Con dichos hallazgos microscópicos se realizó un diagnóstico de granuloma de colesterol.

\section{Díscusilón}

Los granulomas de colesterol consisten en tejido de granulación compuesto por histiocitos, linfocitos y células gigantes multinucleadas, asociado con cristales de colesterol, los cuales en el tejido mamario pueden manifestarse como una secuela tardía de ectasia ductal. Dichas lesiones se producen debido al escape de moléculas de colesterol de los ductos ectásicos hacia el parénquima mamario, actuando como material exógeno con la subsiguiente reacción a cuerpo extraño formando granulomas.

Esta patología se presenta con mayor frecuencia en otros sitios como el oído medio y el proceso mastoideo; también se han reportado casos en menor proporción en riñón, testículo, peritoneo, glándula parótida, hígado y bazo. Los informes de granulomas de colesterol en mama son raros; sin embargo 


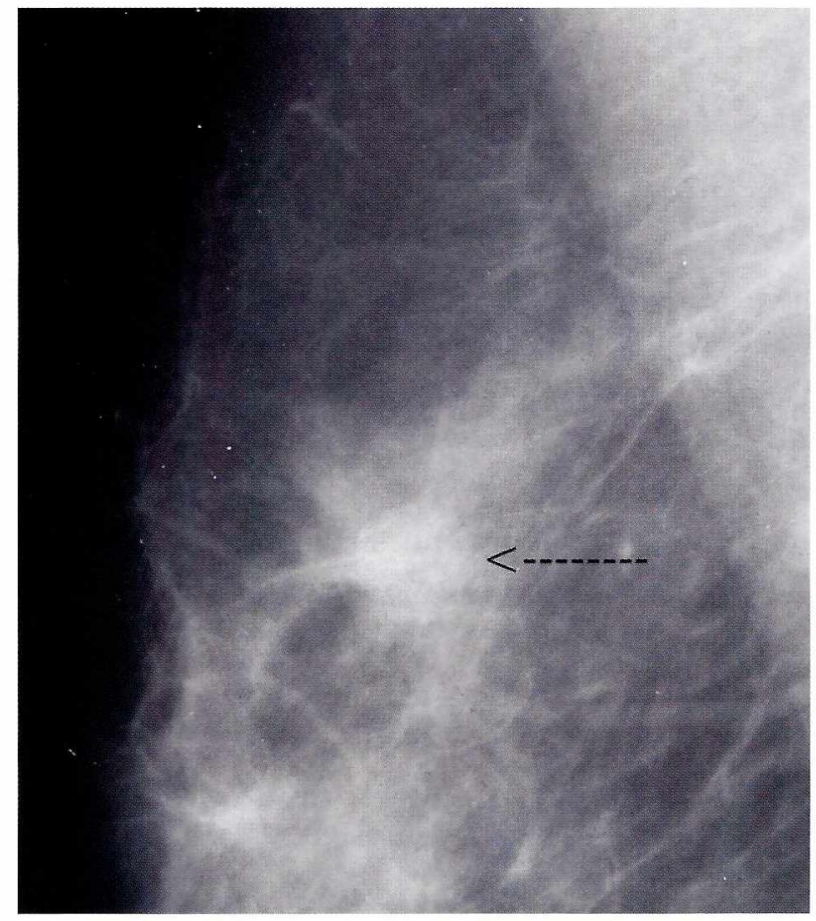

Figura I. Opacidad redondeada por la presencia de un nódulo ubicado en el cuadrante superoexterno derecho, de contornos regulares, pero ligeramente lobulados, sin calcificaciones ni retracción, de carácter inespecífico.

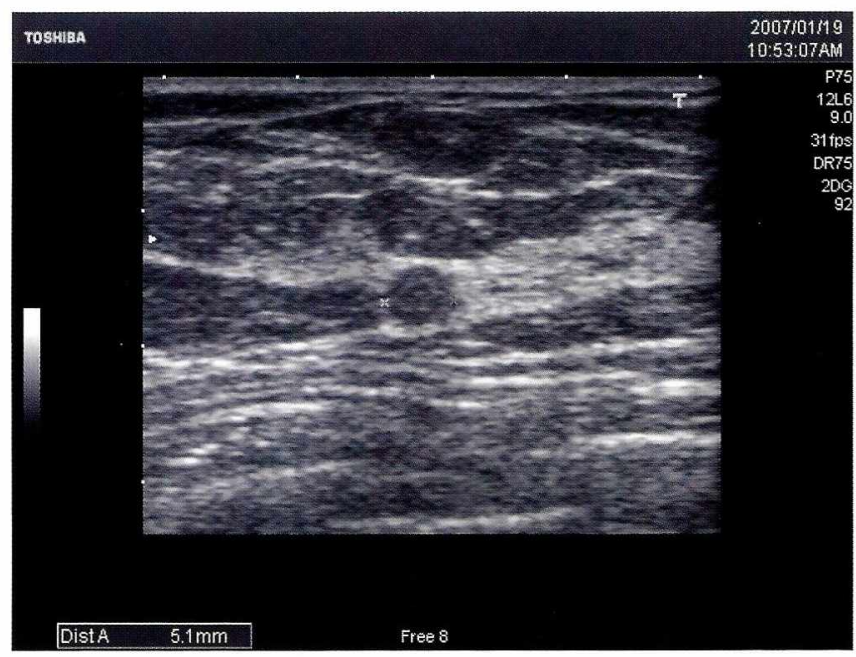

Figura 2. Entre las $x$, se identifica nódulo sólido, ligeramente hipoecoico de contornos regulares y microlobulados, sin sombra sónica, categoría BIRADS - IV, sospechoso de anormalidad.

se encuentran ocasionales casos descritos en la literatura mundial. Debido al carácter benigno de esta patología, su manejo es expectante con estricto seguimiento clínico e imagenológico. Sin embargo, se resalta que existen reportes de casos de carcinoma mamario asociado con granulomas de colesterol, por

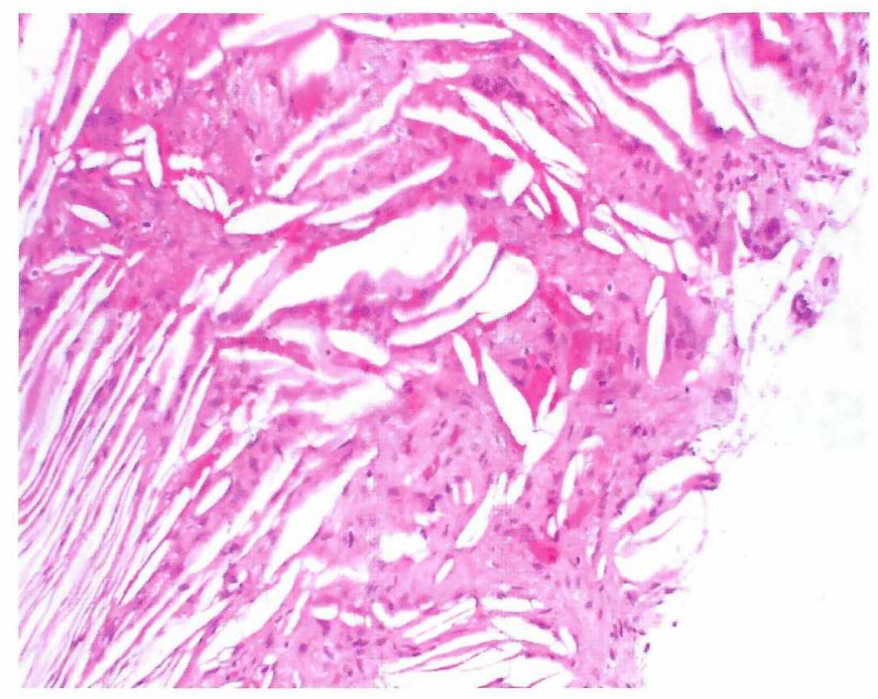

Figura 3. Presencia de granuloma de colesterol constituido por espículas de colesterol, histiocitos y células gigantes multinucleadas.

lo cual es de vital importancia el estudio histológico para establecer el diagnostico final y así prevenir errores y cirugías innecesarias.

\section{Conclusilón}

Con los datos expuestos se concluye que el granuloma de colesterol de la glándula mamaria es una rara patología benigna con características clínicas e imagenológicas que pueden ser indistinguibles de las encontradas en el carcinoma mamario, por lo cual se recomienda su confirmación histológica y seguimiento riguroso de las pacientes.

\section{Lecturas recomendadas}

- Furuhira C, Ohshima A, Shimada K, Kuroki S, Nakano $\mathrm{K}$, Ishikawa M, Yamamoto H, Tanaka M. A case of breast cholesterol granuloma accompanied by cancer. Breast Cancer. 2004;11(2):210-3.

- Ishizaki M, Ohsumi S, Takashima S, Mandai K. Two cases of cholesterol granuloma of the breast. Breast Cancer. 2001;8(2):158-61.

- $\quad$ Osada T, Kitayama J, Nagawa H. Cholesterol granuloma of the breast mimicking carcinoma: report of a case. Surg Today. 2002;32(11):981-4.

- Rosai J. Rosai and Ackerman's Surgical Pathology. 9th ed. Philadelphia: Mosby; 2004.

- $\quad$ Rosen PP. Patología mamaria de Rosen. $2^{\mathrm{a}}$ ed. [Caracas]: Amolca; 2005. 